\title{
Selective Laser Trabeculoplasty
}

\section{Madhu Nagar}

Clayton Eye Centre, Mid Yorkshire Hospital Trust

Wakefield West Yorkshire, UK

\section{INTRODUCTION}

Selective Laser Trabeculoplasty (SLT) is a relatively new treatment designed to lower intraocular pressure (IOP) safely and effectively without the known side effects of argon laser trabeculoplasty (ALT). The mechanism of action is not completely understood but it is thought that the laser selectively targets melanin-laden pigmented cells of the trabecular meshwork, while leaving nonpigmented cells and connective tissues unaffected.

Clinical studies have shown that SLT provides effective reduction of IOP in most eyes with all types of open-angle glaucoma. ${ }^{1}$ Long-term studies, with up to 5 years of follow-up, show sustained pressure lowering effects in more than 60 percent of patients. ${ }^{2,3}$ It thus solves the compliance problem inherent with drug therapy, a factor which severely reduces or negates the effectiveness of all hypotensive drugs. Furthermore, it does so without the side effects of some anti-glaucoma medical therapies without any significant side effects. It is a safe, repeatable alternative to ALT, with minimal tissue damage and can thus be used as primary therapy of glaucoma.

\section{OVERVIEW}

Glaucoma is a multifactorial disease characterized by increased IOP that can lead to damage to the optic nerve, retinal nerve fibers and their cell bodies. It is one of the leading causes of blindness and low vision. Glaucomatous visual loss is preventable through the use of anti-glaucoma medications, laser trabeculoplasty or surgery. The aim of glaucoma treatment is to lower IOP in order to avoid neural damage and/or progression, thereby preserving visual function - with a minimum of side effects at an affordable cost.

Effective medical treatment for glaucoma was first introduced in the later part of nineteenth century. In the recent years, increased numbers of drugs have been developed for the treatment of glaucoma, which have a lower side-effect profile while enabling ophthalmologists to achieve a target IOP in most compliant patients. However, the issue of safety of glaucoma treatment especially that of beta-adrenergic blockers cannot be ignored. ${ }^{4}$ The burden of daily treatment, including cost, inconvenience, tolerability and quality of life are factors that the doctor and patient should discuss because they can lead to poor or noncompliance, followed by progression of diseasedespite early diagnosis and prompt treatment.

\section{LASER TRABECULOPLASTY}

Laser treatment of the trabecular meshwork for glaucoma has become a widely accepted treatment modality since Wise and Witter first introduced the concept of argon laser trabeculoplasty (ALT) in 1979. ${ }^{5}$ Typically, this laser treatment was effective in 90 percent of patients who received a complete $360^{\circ}$ treatment, with decreasing efficiency of 5 to 10 percent per year. ${ }^{5}$ Side effects seen with ALT included inflammatory changes sufficient to induce peripheral anterior synechiae and trabecular scarring. Damage caused by ALT to the anterior chamber (AC) angle limited its usefulness to one treatment. ${ }^{6}$

In 1995, Mark Latina and co-workers first described a new approach for laser treatment for glaucoma-selective laser trabeculoplasty - which demonstrated the potential to cause less damage to the trabecular meshwork. ${ }^{7,8}$ Published studies have shown that SLT provides effective reduction in IOP in most eyes, including those that have undergone a previous ALT treatment. ${ }^{1}$ Studies have also found that SLT is less traumatic to the eye compared to ALT. ${ }^{9}$

\section{MECHANISM OF ACTION}

SLT is thought to selectively target the pigmented cells of the trabecular meshwork without producing collateral thermal or coagulative damage to the adjacent structures. It has a better safety profile due to the minimal energy used, typically four orders of magnitude less than ALT. The IOP lowering effect is derived from selective photothermolysis that is based on three principles:

- First, the absorption of laser energy by intracellular targets is greater than that of surrounding tissues.

- Second, its wavelength matches the absorption wavelength of the target cells and intracellular organelles. 
- Third, a short pulse is used to generate heat that is confined to the pigmented targets.

When all these parameters are met, target specificity is independent of focusing.

Because SLT produces no mechanical effect or heat induction that may cause structural changes to the TM, the mechanism of action for lowering of IOP is thought to be biological, occurring at the cellular level without any of the mechanical effects of ALT. Selective disruption of pigmented cells causes a response resulting in intraocular pressure reduction. The presumed mechanism of action is thought to work like this:

- The laser energy triggers an activation and recruitment of macrophages and monocytes.

- The macrophages then engulf melanin granules and clear them from the trabecular meshwork tissues where they flow out of the eye and return to circulation via Schlemm's canal, which leads to decrease in resistance to aqueous outflow.

- Injury to pigmented trabecular meshwork cells also results in release of at least three specific cytokines that may play an important role in the function of the trabecular meshwork. These cytokines are Interleukin- 1 alpha and beta (IL-1 alpha and beta) and tumor necrosis factor-alpha (TNF-alpha). These are believed to act as growth factors for trabecular cells causing cellular proliferation and extracellular modeling which further invigorates TM filtering and outflow. ${ }^{10}$

As the names suggests, it does appear that SLT selectively targets the melanin-laden pigmented cells of the trabecular meshwork. It is these cells that absorb the laser energy, inducing a primarily biological response in the area of energy absorption, causing the release of cytokines that trigger macrophage recruitment and other changes leading to reduction in IOP reduction. ${ }^{10}$

As shown in Figure 1, the selective nature of this therapeutic form of energy delivery can be seen in the way in which the nonpigmented cells and connective tissues are unaffected following. It is these observations that allow us to conclude that SLT is safe and effective, and can be used with minimal patient follow-up (compared to other glaucoma procedures) (see subsection on complications below). The electron micrographs shown in Figures 2 and 3 further illustrate this point, demonstrating the paucity of structural damage following SLT compared to damage caused by ALT.

\section{OPERATIVE TECHNIQUE}

SLT is a simple outpatient procedure similar to conventional ALT and is performed under topical anesthetic. A frequencydoubled, q-switched, $532 \mathrm{~nm} \mathrm{Nd}$ : YAG laser is used with pulse duration of 3 nsec and a spot size of $400 \mu$ is coupled to a slitlamp delivery system. The pulse duration of $3 \mathrm{nsec}$ is too short for melanin to convert the electromagnetic energy to thermal energy so no heat is generated. The large spot size, around

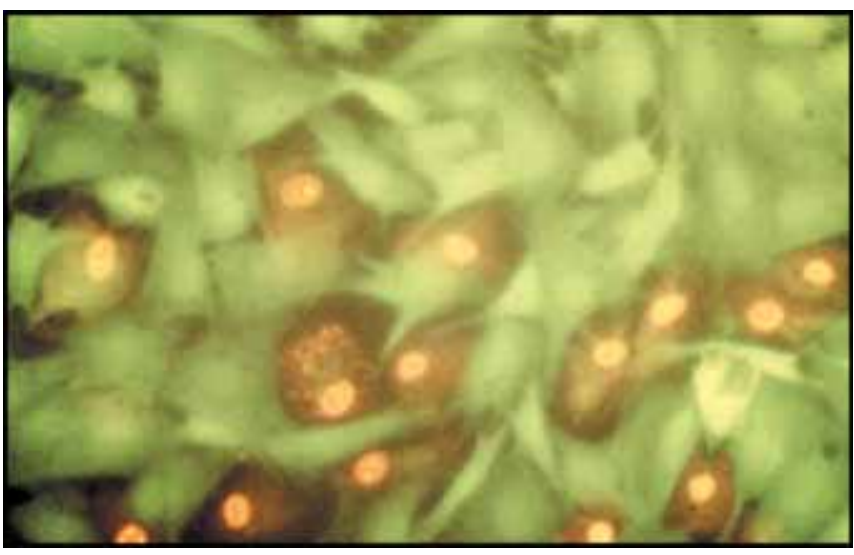

Fig. 1: The melanin laden pigmented TM endothelial cells

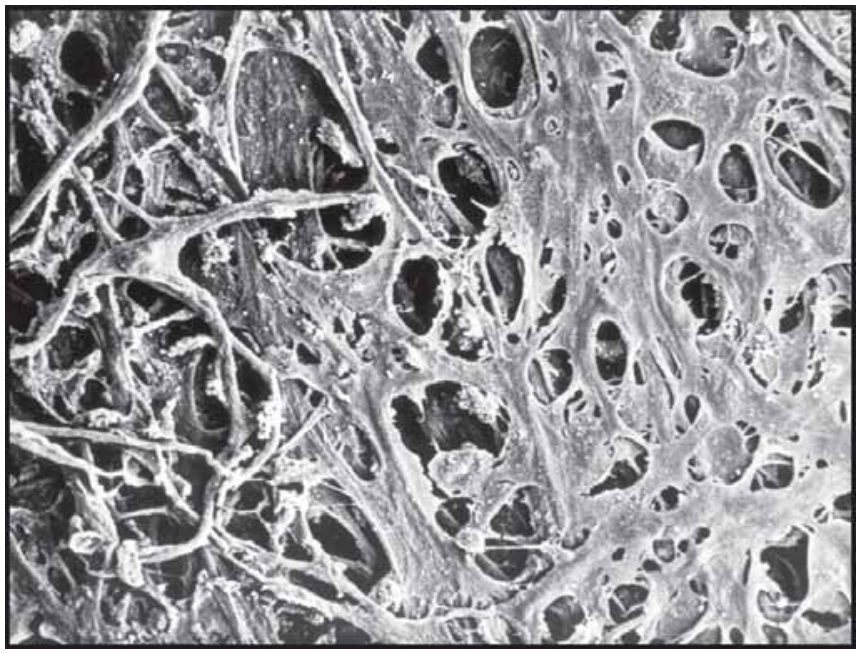

Fig. 2: Electron micrograph of the TM after SLT demonstrating minimal damage to the trabecular beams

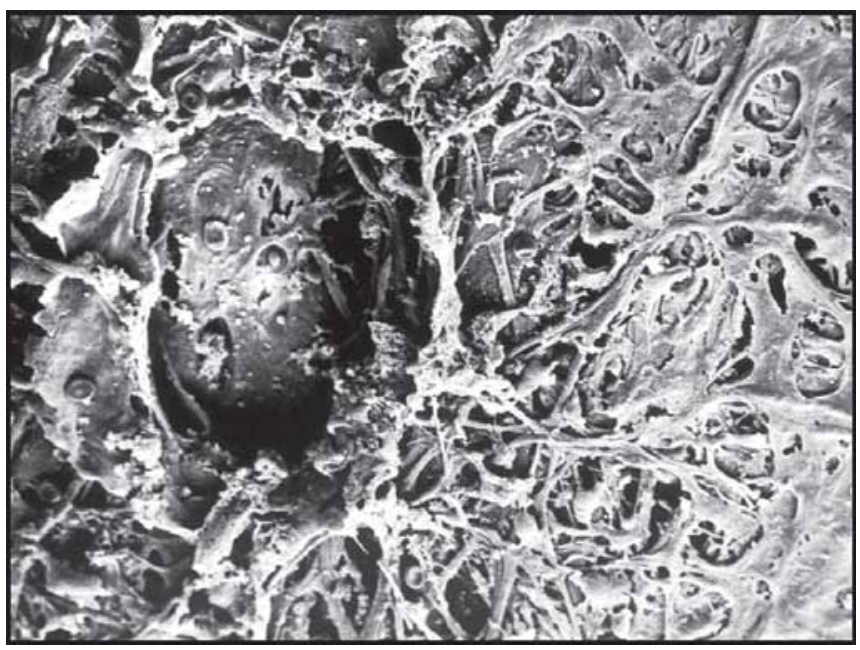

Fig. 3: Electron micrograph of the trabecular meshwork following argon laser trabeculoplasty. The damage to the trabecular beams in considerably more than the damage following selective laser trabeculoplasty 
400 microns in diameter, covers most of the anteroposterior diameter of the trabecular meshwork and makes aiming of the beam compared to the small ALT beam. The laser unit is capable of delivering 0.2 to $2.0 \mathrm{~mJ}$ although energy requirement for SLT varies from 0.6 to $1.2 \mathrm{~mJ}$. The low fluence (energy per unit area) of the SLT is some 6500 times lower than that of the ALT.

The energy level is titrated to the degree of trabecular pigmentation. The greater the pigmentation the less energy required. To determine the optimum energy level the power setting is initially set at $0.8 \mathrm{~mJ}$, and then the energy level is increased by $0.1 \mathrm{~mJ}$ until bubble formation is observed or if bubble formation is already noted at the initial energy level, the laser energy is reduced by $0.1 \mathrm{~mJ}$. In heavily pigmented eyes it is recommended to start with the lower power setting of $0.4 \mathrm{~mJ}$ and then increase the energy level as necessary. To perform the treatment, the ophthalmologist places $50 \pm 5$ contiguous spots over $180^{\circ}$ of the trabecular meshwork or $100 \pm 5$ contiguous spots over $360^{\circ}$ of trabecular meshwork. There is no sufficient data yet to determine whether $360^{\circ}$ treatment is preferable to treating half of the AC angle circumference, but it seems to be the case, at least in angles that are not heavily pigmented.

Many practitioners give brimonidine or apraclonidine drops prior to the treatment in order to reduce postoperative IOP spikes. Postoperative medications consist of nonsteroidal antiinflammatory drops three to four times a day for three to five days. If patients are on anti-glaucoma drops prior to SLT, the typical procedure is to leave these unchanged.

\section{INDICATIONS, INCLUSION AND EXCLUSION CRITERIA}

The indications for SLT are newly diagnosed POAG patients or POAG patients who are uncontrolled on medical therapy, previous but failed ALT treatment and ocular hypertensives requiring treatment to lower IOP. SLT has been shown to be effective in patients with exfoliative and pigmentary glaucomas.

\section{Adverse Effects}

Adverse effects are minimal and transient. They are mild discomfort, IOP spike and increased anterior chamber activity for few days but no case of persistent iritis. Vision is blurred for five to ten minutes after laser delivery and sore eyes for 3 to 5 days post-laser treatment. Occasionally, patients do complain of headaches or precipitation of migraine. There was no occurrence of peripheral anterior synechiae. There was one report of four case of paradoxical prolonged IOP increase in heavily pigmented eyes.

\section{Benefits of SLT}

- SLT results in a biological response that increases aqueous drainage and lowers IOP.

- $\quad$ SLT does not cause scarring of the trabecular meshwork.

- It may reduce or eliminate the lifelong need for anti-glaucoma medications

- In turn, reducing or eliminating the inconvenience of daily medication regimens

- It solves the compliance issue which drastically limits the effect of drug therapy.

- SLT can help avoid adverse reactions to anti-glaucoma medications.

\section{Clinical Trials}

SLT was found effective in repeated clinical trials to produce long-term reduction in IOP in most cases of all types of openangle glaucoma as seen in Table 1, while Table 2 shows success rates from a number of SLT trials.

Table 1: SLT—Long-term IOP reduction

\begin{tabular}{|c|c|c|c|c|}
\hline Study & $N$ (eyes) & Follow up (years) & $\mathrm{IOP}^{\circledR} \mathrm{mm} \mathrm{Hg}$ & $I O P^{\circledR}$ percent \\
\hline \multirow[t]{3}{*}{ Gracner 06} & 90 & 2 & 5.8 & 25.5 \\
\hline & & 4 & 5.2 & 23.1 \\
\hline & & 6 & 5.4 & 22.8 \\
\hline \multirow[t]{2}{*}{ Weinand 05} & 52 & 3 & 5.5 & 24.5 \\
\hline & & 4 & 6.3 & 29.3 \\
\hline Lai 04 & 58 & 5 & 8.6 & 32.1 \\
\hline Juzych 04 & 41 & 5 & 5.9 & 21.2 \\
\hline
\end{tabular}


Selective Laser Trabeculoplasty

\begin{tabular}{|c|c|c|c|c|}
\hline Study & $N$ (eyes) & Follow up (years) & Definition & $\%$ Success \\
\hline Hodge & 72 & 1 & $>20$ percent & 60 \\
\hline \multirow[t]{4}{*}{ Juzych } & 41 & 3 & $>3$ mm Hg & 46 \\
\hline & & & $>20$ percent & 38 \\
\hline & & 5 & > 3 mm Hg & 32 \\
\hline & & & $>20$ percent & 31 \\
\hline Lai 2005 & 24 & 5 & $>21$ mm Hg & 82 \\
\hline Gracner 2006 & 90 & 6 & $>20$ percent & 59 \\
\hline
\end{tabular}

Since its introduction, there has been just one clinical study where SLT was deemed to be a failure. In a retrospective study of 94 eyes for 14 months the overall failure rate was 68 to 92 percent. However, this study was performed in a tertiary referral center on patients who were on multiple anti-glaucoma medications and had a previous history of glaucoma surgery. The authors concluded that the study was a failure due to the relatively minor reduction in IOP - from a mean preoperative IOP of $17.6 \mathrm{~mm} \mathrm{Hg}$ to a post-SLT mean IOP of $15.5 \mathrm{~mm} \mathrm{Hg.}{ }^{11}$

Overall, the IOP reduction achieved by SLT and the longterm effectiveness did not differ according to the type of glaucoma or whether the SLT treatment was primary or secondary. There was no differentiation in results due to:

- Age

- Gender

- Race

- Family history

- Other glaucoma risk factors

- Type and severity of OAG

- Trabecular meshwork pigmentation (unlike ALT)

- Pseudoexfoliation

- Number of anti-glaucoma medications (unlike ALT)

- Previous ALT (unlike ALT)

- Presence of systemic hypertension

- Diabetes mellitus ${ }^{12}$

The only variable that seems to determine the extent of the reduction in IOP is the level of IOP prior to SLT treatment- the higher the IOP, the greater the reduction in IOP and vice versa.

The response to SLT treatment is immediate, typically seen on the first day after treatment in most of the patients, although there are about 6 to 8 percent of patients who are late or slow responders. In these patients, a reduction in IOP typically occurs over a 4 to 12 week period. It has also been observed that there is often a sympathetic effect in the untreated eye (if only one eye is treated), with a 10 to 12 percent reduction in IOP having been reported. ${ }^{8}$

\section{DISCUSSION}

Selective laser trabeculoplasty was developed as an alternative to ALT for treatment of OAG. By selectively targeting only the pigmented TM cells and avoiding collateral thermal damage to surrounding cells and structures, SLT avoids the permanent scarring of the TM that is seen with ALT.

SLT is a safe and effective means of lowering intraocular pressure. The effect is sustained over a period of 2 to 6 years as shown by various studies. ${ }^{1-3,12-14} \mathrm{Q}$-switched trabeculoplasty does not cause collateral thermal damage hence, making it repeatable, even in failed ALT patients. ${ }^{1}$ The procedure is indicated in medically uncontrolled OAG and OHT patients, newly diagnosed OAG and OHT, OAG and OHT patients intolerant to medical treatment as well as in patients with uncontrolled IOP who have undergone a previous ALT.

In our own series, as well as other clinical studies, SLT has been proven safe and effective. ${ }^{1-3,8,12-17}$ It is a useful first-line treatment in newly diagnosed patients, as well as being valuable in known glaucoma patients on medical treatment who are either non-compliant, have developed intolerance to anti-glaucoma drops or are experiencing local or systemic side effects (as replacement therapy).

Noncompliance is a major cause of visual loss in patients with glaucoma. The latest diagnostic techniques (which attempt to detect glaucoma prior to any visual loss) and treatment advances (which attempt to hold the disease at its current stage and prevent further optic nerve damage) are of no benefit in medical management if the patient is noncompliant. Among the reasons for Poor/Noncompliance are: asymptomatic disease, active social life, old age, arthritis, senile dementia to name but a few. 


\section{The advantages of SLT are:}

- It is not dependent on patient compliance

- It does not involve the ongoing expenses of medications

- It causes no systemic side effects associated with medical therapy

- It avoids risks associated with filtration surgery, such as hemorrhage, infection or cataract formation.

I see trabeculoplasty as a win-win-win situation because its cost-effective, time-effective and produces real benefits for the patient.

\section{$S L T$}

- Is as effective as ALT in IOP reduction without causing structural damage

- Is an effective modality for long term IOP reduction

- Is effective in most cases of most types of glaucoma

- Is as effective as any single drug for IOP reduction

- Effect is independent from most parameters except initial IOP

- Causes neither long term nor significant side effects

- Can be used as initial therapy in preference to drugs

- Is enhanceable and repeatable

- Has minimal follow-up requirements.

The author acknowledges the help rendered by Michael Belkin, MA, MD of Tel Aviv University in the preparation of this review.

\section{REFERENCES}

1. Damji KF, Shah KC, Rock WJ, et al. Selective laser Trabeculoplasty vs Argon laser Trabeculoplasty: a prospective randomized clinical trial. Br J Ophthalmol 1999; 836:718-22.

2. Gracner T, Falez M, Gracner B, Pahor D. Long-term follow-up of selective laser trabeculoplasty in primary open-angle glaucoma. Klin Monatsbl Augenheilkd 2006;223:743-7. German.

3. Weinand FS, Althen F. Long-term clinical results of selective laser trabeculoplasty in the treatment of primary open angle glaucoma. Eur J Ophthalmol 2006;16:100-4.

4. Frishman WH, Kowalski M, Nagnur S, Warshafsky S, Sica D. Cardiovascular considerations in using topical, oral, and intravenous drugs for the treatment of glaucoma and ocular hypertension: focus on beta-adrenergic blockade. Heart Dis 2001;3:386-97.

5. Wise JB, Witter SL. Argon therapy for open angle glaucoma: a pilot study. Arch Ophthalmol 1979;97:319-22.

6. The Glaucoma Laser Trial (GLT) and Glaucoma Laser Trial Follow-up Study: Results. Am J Ophthalmol 1995;120:718-31.

7. Latina MA, Park C. Selective targeting of trabecular meshwork cells: in vitro studies of pulsed and CW laser interactions. Exp Eye Res 1995;60:359-72.
8. Latina MA, Sibayan SA, Shin DH, et al. Q-switched $532 \mathrm{~nm}$ Nd: YAG laser trabeculoplasty (Selective laser trabeculoplasty): A multi-center pilot study. Ophthalmology 1998;105:2028-88.

9. Kramer TR, Noecker RJ. Comparison of the morphologic changes after selective laser trabeculoplasty and argon laser trabeculoplasty in human eye bank eyes. Ophthalmology 2001;108:773-9.

10. Alvarado JA, Alvarado RG, Yeh RF, Franse-Carman L, et al. A new insight into the cellular regulation of aqueous outflow: how trabecular meshwork endothelial cells drive a mechanism that regulates the permeability of Schlemm's canal endothelial cells. Br J Ophthalmol 2005;89:1500-5.

11. Song J, Lee PP, Epstein DL, Stinnett SS, Herndon LW Jr, Asrani SG. High failure rate associated with 180 degrees selective laser trabeculoplasty. J Glaucoma 2005;14:400-8.

12. Hodge WG, Damji KF, Rock W, Buhrmann R, Bovell AM, Pan Y. Baseline IOP predicts selective laser trabeculoplasty success at 1 year post-treatment: results from a randomised clinical trial. Br J Ophthalmol 2005;89:1157-60.

13. Juzych MS, Chopra V, Banitt MR, Hughes BA, Kim C, Goulas MT, Shin DH. Comparison of long-term outcomes of selective laser trabeculoplasty versus argon laser trabeculoplasty in openangle glaucoma. Ophthalmology 2004;111:1853-9.

14. Lai JS, Chua JK, Tham CC, Lam DS. Five-year follow up of selective laser trabeculoplasty in Chinese eyes. Clin Experiment Ophthalmol 2004;32:368-72.

15. Lanzetta $P$, Menchini U, Virgili G. Immediate intraocular pressure response to Selective laser trabeculoplasty. $\mathrm{Br} \mathrm{J}$ Ophthalmol 1999;83:29-32

16. Sholomo Melamed, Guy J Ben Simon, et al. Selective Laser Trabeculoplasty as primary treatment for open angle glaucoma: a prospective, non-randomized study. Arch Ophthalmol 2003;121:957-60.

17. Nagar M, Ogunyomade A, O’Brart DPS, Howes F, Marshall J. A randomized prospective study comparing selective laser trabeculoplasty with latanoprost for the control of intraocular pressure in ocular hypertension and open angle glaucoma. $\mathrm{Br} \mathrm{J}$ Ophthalmol 2005;89:1413-7.

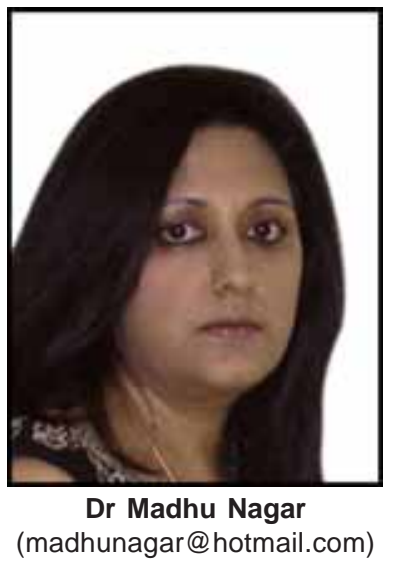

